\title{
Measuring Potassium in Muscle Tissue Utilizing an Atomic Absorption Spectrometer Validation of an Adaptation for a Whole-body Potassium Counting Method
}

\author{
Anthony R. Horner ${ }^{\$}$, Rose A. Clark ${ }^{\$}$, Stephen M. LoRusso+, \\ and Edward P. Zovinka $\$$ \\ $\$$ Department of Chemistry \\ +Department of Physical Therapy \\ Saint Francis University \\ 117 Evergreen Drive \\ Loretto, Pennsylvania 15940 USA
}

Received: May 5, $2011 \quad$ Accepted: September 12, 2011

\begin{abstract}
Potassium is a cation important for a properly functioning body. It is especially significant for nerves, kidneys, and muscles. The concentration of potassium ions in muscle tissue was determined using an atomic absorption spectrometer operating in emission mode. The meat samples were flash frozen using liquid nitrogen, further ground using a mortar and pestle and then digested by immersing the processed meat in a hydrochloric acid solution. The potassium concentrations in muscle tissue were found to range from $2.76-4.66 \mathrm{~g} \mathrm{~K}^{+} / \mathrm{kg}$ of beef sample.
\end{abstract}

\section{INTRODUCTION}

Potassium has a number of biochemical functions including being important in neuron function in both the brain and nerves, which are directly related to muscular control and movement [1]. Potassium is essential for a healthy lifestyle and is oftentimes found in high concentrations in many foods including: meats, fish, vegetables, fruits, juices, dairy products, and whole grains [1]. For these reasons, it is oftentimes beneficial for health care professionals to know the $\mathrm{K}^{+}$levels in muscle tissue as an indicator of patient health. However, the most common technique of determining these levels involves taking a blood sample from the patient. The development of a non-invasive scintillation procedure for use on living tissue without chemical destruction could reduce patient stress along with providing a technique for the localized detection of potassium rather than an overall view of the concentration. [2] A non-invasive detection method could provide a quantitative benchmark into muscle tissue growth and development. To calibrate this non-invasive scintillation based $\mathrm{K}^{+}$detector, which is under development, the amount of $\mathrm{K}^{+}$ions present in beef phantoms (samples provided by PSU) needed to be determined. Potassium levels are routinely measured in the chemistry laboratory using atomic absorption. The goal of this project is to develop a sample preparation method for potassium extraction from meat samples to use with the atomic absorption spectrometer.

Preliminary samples used for analysis were apple juice, a commercially available sports drink, and a banana. This initial experimentation was subsequently followed with testing various ground beef samples, and the beef phantoms using two newly developed digestion methods. Literature states that ground beef has a concentration of 1.9 grams of potassium ion per $\mathrm{kg}$ of adipose tissue and between 3.1 and 3.5 grams of potassium ion per kilogram 
of lean muscle tissue [3]. Concentrations of potassium from the currently developed methods are presented and compared to literature values.

\section{EXPERIMENTAL PROCEDURE}

\section{a. Materials}

Potassium chloride was used as purchased for standards at $99.0 \%$ purity (Sigma Aldrich). The apple juice, sports drink, and banana were purchased from Smithmeyer's Superette, Loretto, $\mathrm{Pa}$. Ground Beef for preliminary method testing was purchased from local butchers or supermarkets (Pudliner's Packing, Johnstown, $\mathrm{Pa}$. and Smithmeyer's Superette, Loretto, Pa.). Beef phantoms tested on the whole-body counting method were purchased from Giant ${ }^{\circledR}$ Grocery Store (State College, Pa.).

\section{b. Experimental}

A Bel-Art, Scienceware LiquidCooled Mortar was used for the digestion of the meat samples. An Orbit Shaker Model 3520 was used for digestion (Labline Instruments, Inc). A DuPont Instruments: Sorvall $\mathrm{B}$ RC-5B Refrigerated Superspeed with a DuPont Instruments Sorvall $\AA_{\text {S S-34 }}$ Insert for Nalgene Oak Ridge Centrifuge Tubes Model FEP was used for centrifugation. The Atomic Absorption Spectrometer was a Thermo $S$ Series spectrometer operating under emission conditions (analysis wavelength $766.5 \mathrm{~nm}$ ). Flame type: air/acetylene with a flow rate of $1.1 \mathrm{~L} / \mathrm{min}$.

c. Initial Testing:

Initial testing of the atomic absorption spectrometer for the detection of potassium in the emission mode was carried out through the analysis of apple juice, a commercially available sports drink, and a banana. The apple juice and sports drink were both tested on a $1 / 1000^{\text {th }}$ dilution and a $1 / 5000^{\text {th }}$ dilution, respectively. The banana was tested using a simple digestion method. The method used one third of the banana. The banana was blended with seven times the sample mass of water. From the solution created, $25 \mathrm{~mL}$ was combined with $25 \mathrm{~mL}$ of
$1 \mathrm{M} \mathrm{HCl}$. The banana solution was sonicated for 20 minutes, followed by vacuum filtration, and dilution. The final dilution of the banana solution was $1 / 1000^{\text {th }}$.

\section{Potassium in Meat Samples}

\section{a. Method 1}

The first method consisted of measuring approximately 5 grams of ground beef. The samples were then soaked in a beaker containing a hydrochloric acid solution. Half of the samples were tested in a $1 \mathrm{M}$ acid solution, while the other half were tested in a $3 \mathrm{M}$ acid solution. The solutions were soaked on a ratio of 1 gram of meat to $5 \mathrm{~mL}$ of hydrochloric acid. The concentrations of potassium were measured over the course of several days by removing a small $20 \mu \mathrm{L}$ aliquot of the solution that had been soaking with the meat. This was followed by a dilution with $\mathrm{DI}$ water, and aspiration through the atomic absorption spectrometer without further sample preparation.

b. Method 2

The frozen ground beef was ground to a powder in an insulated stainless steel mortar and large ceramic pestle while utilizing liquid nitrogen for cooling. These ground samples were separated into four fractions, and the masses were recorded. The samples were soaked in both $1 \mathrm{M}$ and 3 $\mathrm{M} \mathrm{HCl}$ and placed on an orbit shaker table at 2,000 RPM for two days to allow for digestion. Each sample was then centrifuged at 10,000 g-force for fifteen minutes to remove solids. The supernatant liquid was decanted and the liquid volume was recorded for an accurate analysis of concentration. Centrifuging was then repeated under the same conditions and the supernatant liquid was removed again and combined with the first sample taken. After this, a $10 \mu \mathrm{L}$ sample was diluted with deionized (DI) water to $50.00 \mathrm{~mL}$ for analysisusing atomic emission.

\section{RESULTS AND DISCUSSION}

Immediately after preparation, samples were analyzed using the atomic absorption spectrometer running in emission 

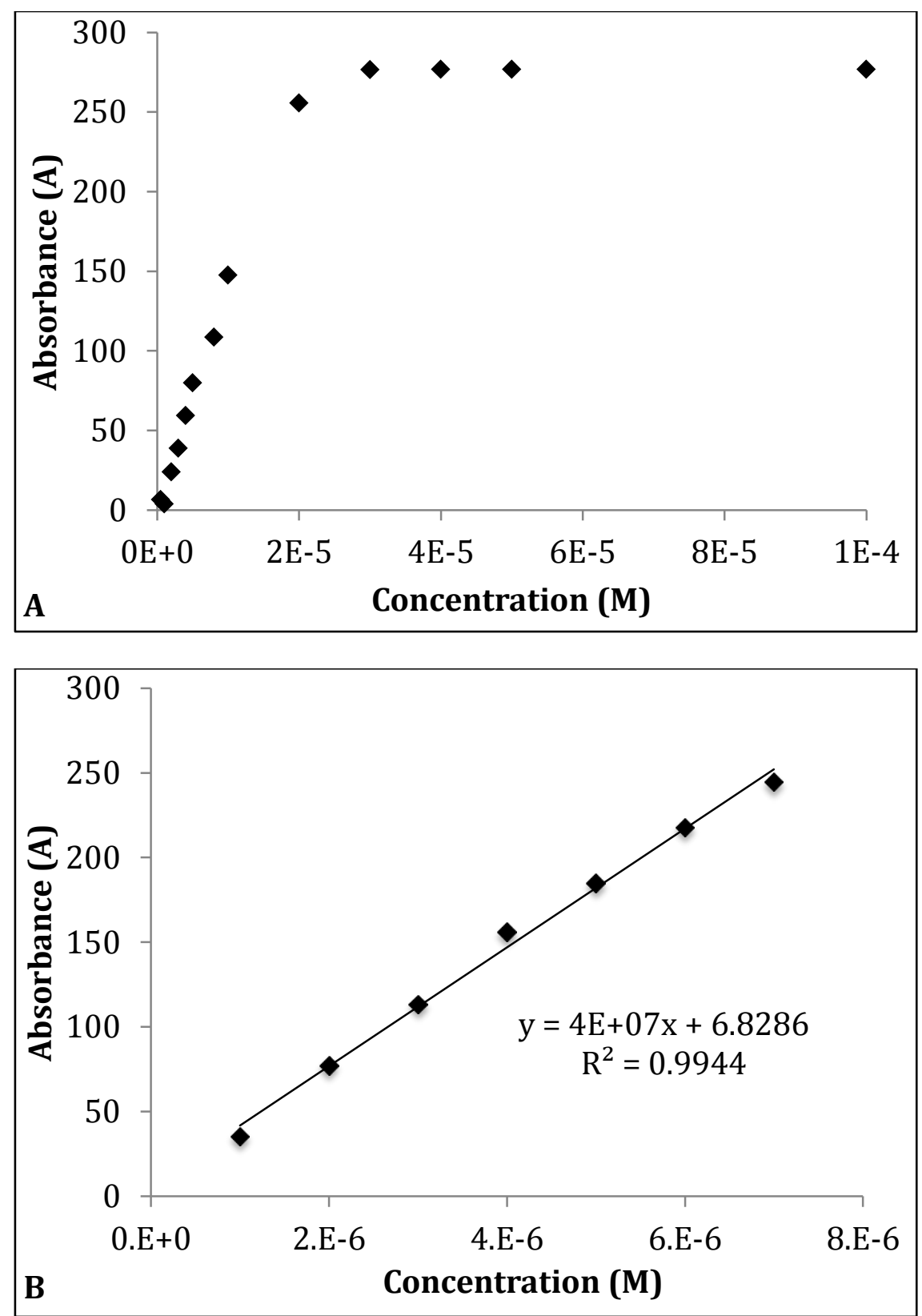

Figure 1. $\mathrm{KCl}$ Atomic Absorption Spectrometer Calibration Curves: A) Initial Concentration Range Testing; B) Final Concentration Curve

mode. The emission mode provided a lower limit of detection for potassium ions when compared to the absorption mode. A calibration curve was generated to check linearity from micromolar levels up to millimolar levels (Figure 1A). As seen in Figure $1 \mathrm{~A}$, at relatively high concentrations, the absorbance values level off. The selected concentration range for the detection of potassium was from $1 \mu \mathrm{M}$ to 7 $\mu \mathrm{M}$ as it provided the best linear calibration curve, and had a correlation coefficient of 0.9944 (Figure 1B). The standard range of 1 $\mu \mathrm{M}$ to $7 \mu \mathrm{M}$ centered the standard solutions in the linear range.

Initial sample testing was carried out with apple juice, a sports drink, and a banana. The apple juice and sports drinks were selected due to the ease of sample preparation. The banana was chosen for 


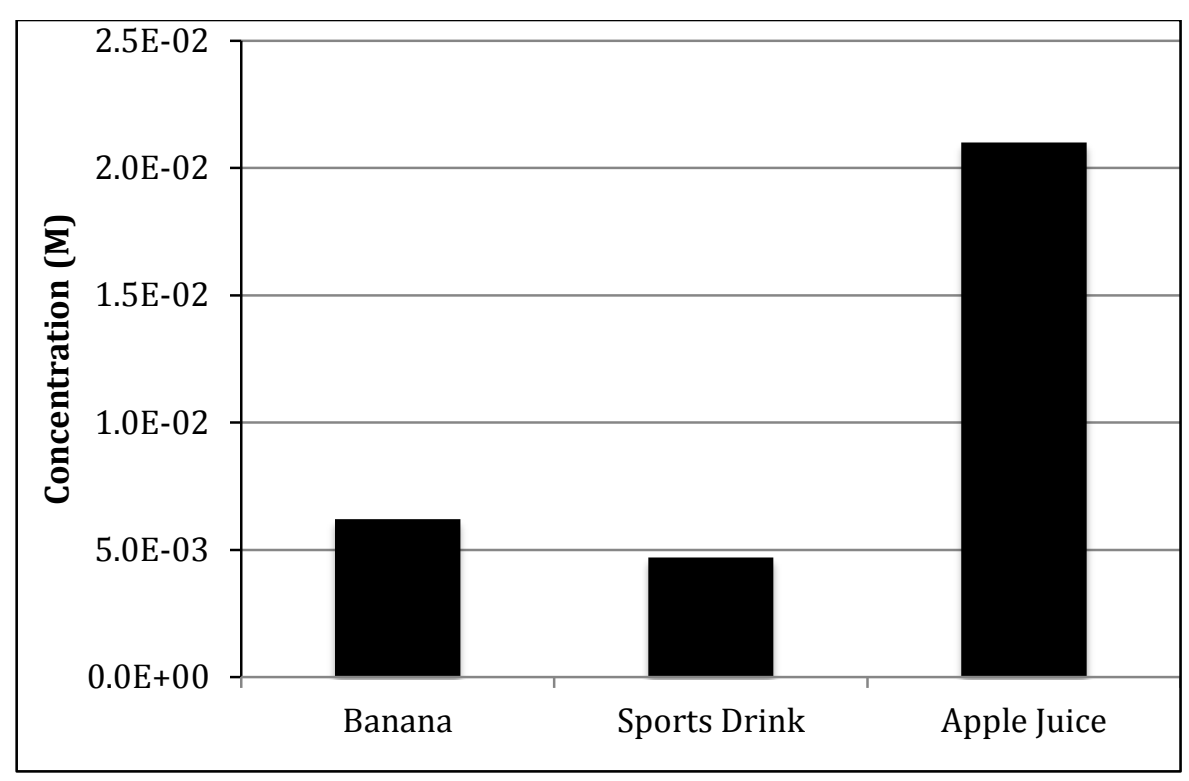

Figure 2. Potassium Ion Concentration in Commercial Products

\begin{tabular}{|c|c|c|}
\hline Sample & $\mathbf{K}^{+}$ & Expected \\
\hline Banana & $6.20 \times 10^{-3}$ & $7.9 \times 10^{-2}-8.5 \times 10^{-2} \mathrm{M}$ \\
\hline Sports & $4.70 \times 10^{-3}$ & $3.2 \times 10^{-3} \mathrm{M}$ (labeled) \\
\hline Apple & $2.10 \times 10^{-2}$ & $2.7 \times 10^{-2} \mathrm{M}$ (labeled) \\
\hline
\end{tabular}

Table 1. Potassium lon Concentration in Commercial Products

pretesting on the basis of beginning the development of a general digestion method prior to starting the muscle tissue method development. The expected concentrations of the juice and the sport drink were calculated from the nutrition facts as labeled on the bottles. Similarly, in the case of the banana, upper and lower limits were researched, which in turn determined the concentration of the potassium ions present [4-5]. In the testing for the sports drink, the average concentration obtained was higher than the expected concentration, whereas the apple juice was a little lower than the expected concentration and the banana was well below the expected amount of potassium ions (Figure 2, Table 1). This may be accounted for due to natural variation in banana and apple growth, and the labels of the bottles being upper or lower tolerances depending on substance. The experimentation on the apple juice, sports drink, and banana was performed once (with each sample measured three times) as a preliminary trial before running the muscle tissue method and for practice running the instrument.

The concentration of potassium ions determined in ground beef samples for the two methods can be seen in Table 2. Seven beef phantom samples obtained from Dr. LoRusso were tested in this research project. The composition of the meat samples was unknown until all testing was completed. After the testing was completed, the ratio between the percentage of fat in the sample obtained from Dr. LoRusso compared with the percentage of muscle mass was used as a reference to the potassium ion concentrations obtained experimentally. On average, muscle tissue contains between 3.1 and 3.5 grams of potassium ions per kilogram, while fat tissue contains just 1.9 grams of potassium ions per kilogram [3]. These values, in conjunction with the labeled percentage of the ground beef, were used to determine a predicted potassium level present in the meat phantom through a simple calculation. The calculation entailed the sum of the fat 


\begin{tabular}{|c|c|c|c|c|c|c|}
\hline Phantom & $\begin{array}{c}\text { Meat:Fat } \\
\text { Ratio }\end{array}$ & $\begin{array}{l}\text { Predicted } \\
\mathrm{g} \mathrm{K}^{+} / \mathbf{k g}\end{array}$ & $\begin{array}{c}\text { Method } 1 \\
\mathrm{~g} \mathrm{~K}^{+} / \mathbf{k g}\end{array}$ & $\begin{array}{c}\text { Stand. Dev. } \\
n=6\end{array}$ & $\begin{array}{c}\text { Method } 2 \\
\mathrm{~g} \mathrm{~K}^{+} / \mathbf{k g}\end{array}$ & $\begin{array}{c}\text { St. Dev. } \\
n=8\end{array}$ \\
\hline 2 & unknown & unknown & 2.73 & 0.04 & 4.66 & 1.39 \\
\hline 3 & $93: 7$ & 3.20 & 2.77 & 0.94 & 4.34 & 0.62 \\
\hline 4 & $97: 3$ & 3.26 & 2.01 & 0.94 & 4.11 & 0.97 \\
\hline 1 & 73:27 & 2.92 & 2.27 & 0.20 & 2.82 & 0.25 \\
\hline 5 & $97: 3$ & 3.26 & - & - & 3.92 & 0.64 \\
\hline 6 & $85: 15$ & 3.09 & - & - & 4.06 & 1.32 \\
\hline 7 & $73: 27$ & 2.92 & - & - & 2.76 & 0.50 \\
\hline
\end{tabular}

Table 2: Comparison of Potassium lon Concentration in Beef Phantoms (2 day acid digestion)

percentage times $1.9 \mathrm{~g} \mathrm{~K}^{+} / \mathrm{kg}$ and the muscle percentage times $3.3 \mathrm{~g} \mathrm{~K} / \mathrm{kg}$. The value of $3.3 \mathrm{~g} \mathrm{~K}^{+} / \mathrm{kg}$ was used for the value for the muscle composition due to being the middle of the range of $3.1 \mathrm{~g} \mathrm{~K}^{+} / \mathrm{kg}$ to $3.5 \mathrm{~g}$ $\mathrm{K}^{+} / \mathrm{kg}$. Phantom testing was completed on method 1 for the first four samples. The experimentally determined $\mathrm{K}$ concentrations were found to be lower than the expected values. For example, it was expected that Phantom \#4 would have approximately 3.26 $\mathrm{g} \mathrm{K}^{+} / \mathrm{kg}$ of beef, but only $2.01 \mathrm{~g} \mathrm{~K}^{+} / \mathrm{kg}$ of beef was observed (Table 2). In order to determine if the method was in fact extracting all of the available $\mathrm{K}^{+}$in the beef, the method was modified. It can be seen in Table 1 that Method 2 provided an increase in the concentration of potassium ions extracted from each phantom. For samples 1 through 4, there was an average increase of $1.54 \mathrm{~g} \mathrm{~K}^{+} / \mathrm{kg}$ when switching from Method 1 to Method 2.

Most of the samples provided values that were consistent within one standard deviation of the predicted potassium ion levels. Some of the sample values were outside the predicted range. In the cases of samples 2 through 6 , the values were above the theoretical maximum of $3.5 \mathrm{~g} \mathrm{~K}^{+} / \mathrm{kg}$. Figure 3 shows a relationship between the concentration of potassium ions and the percent muscle composition. The lack of a linear trend as compared with the predicted concentrations (dotted line), may be due to the commercial addition of potassium lactate $\left(\mathrm{KC}_{3} \mathrm{H}_{5} \mathrm{O}_{3}\right)$ to the meat samples. Large companies add potassium lactate to ground beef to preserve quality during shipping for defending against yeasts and fungi [6]. With the addition of potassium lactate, the potassium in these treated samples may not reflect the true potassium level in the muscle tissue. To explore this possibility, meat samples were obtained from local butchers without potassium lactate for comparison to the beef phantoms tested. In Figure 4 it can be seen that no distinct differences were observed for the "Store" meat (local butchers) and the 4 beef phantoms measured using Method 1 . The similarity between the two data sets indicates that potassium lactate addition is most likely not the source of the high potassium levels. Reviewing the method and EPA methods [7] for soil digestion it was found that addition of alkali salts will enhance the $\mathrm{K}$ signal due to decreased ionization. The meat samples will contain additional salts due to the nature of the complex sample. The standards in this case did not contain additional salts so the ionization of $\mathrm{K}$ would cause the signals to be slightly lower than with the electron donating salts. The higher values for the meat samples compared to the predicted values would be reasonable with the differences in ionization of $\mathrm{K}$ for the standards. Future studies will investigate the ionization issue further.

Another variable was simply sampling location from the sample of meat, as bovine tissue is not a homogenous tissue. In removing two samples from the same container of meat, two separate samples may have a sizeable difference in lean to fat concentration. To counter this problem, multiple samples were tested and the average and standard deviations were calculated. In Method 1, six samples were tested for each meat sample, and in Method 


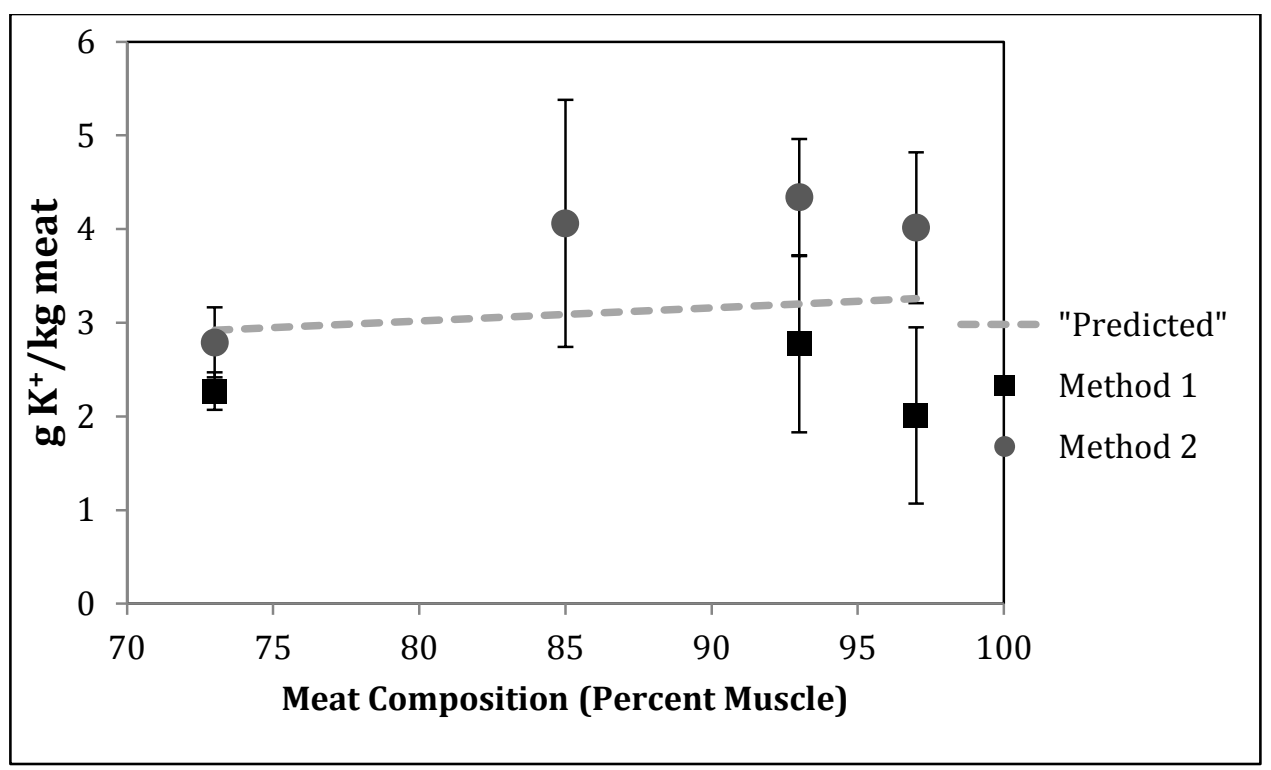

Figure 3. Correlating Muscle Composition to Potassium Ion Concentration for Two Different Digestion Methods.

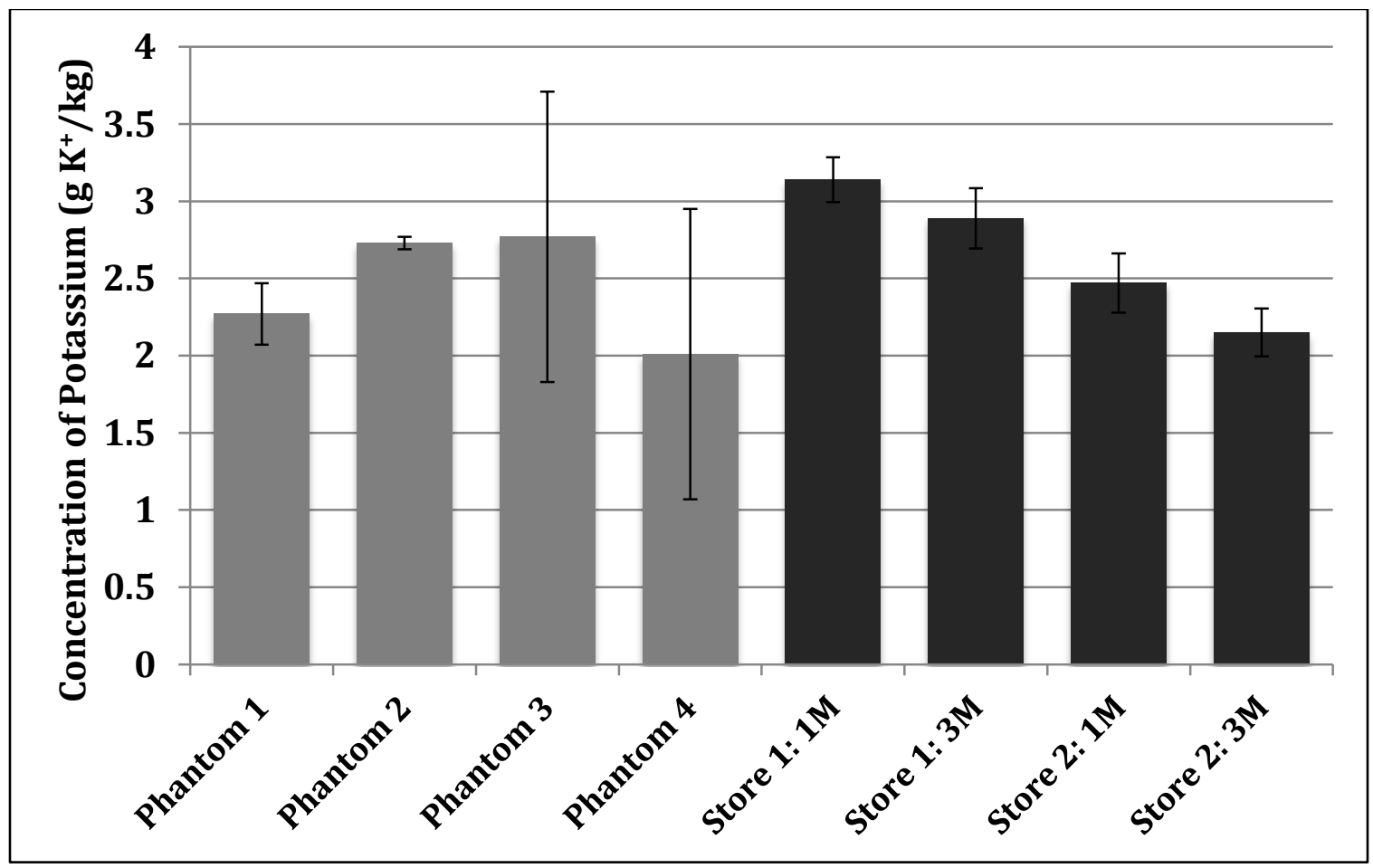

Figure 4. Method 1 Comparison of Potassium Lactate Treated Meat with Untreated Meat: Light Gray: Treated with Potassium Lactate; Dark Gray: Untreated

2, eight samples were tested from each meat sample.

The addition of liquid nitrogen to Method 2 allowed for complete freeze fracturing of the cells, which increased the amount of potassium ions extracted from the meat. Additionally, the incorporation of a shaker table in conjunction with sealed 
centrifuge tubes allowed for a period of agitation throughout the digestion process. The sealed centrifuge tubes were a much better option than beakers sealed with Parafilm. In the first method, the meat tended to stick to the side of the beakers. Agitating the meat phantoms using a shaker table prevented sticking to sidewalls and allowed for the complete digestion of the meat. The use of a centrifuge removed the liquid from the sample and allowed for the specific volume of liquid to be measured precisely. And finally, replacing a ceramic mortar and pestle with a stainless steel mortar and pestle reduced breakage at liquid nitrogen temperatures $\left(-195.79{ }^{\circ} \mathrm{C}\right)$. By using a commercially available liquid nitrogen mortar and pestle, the liquid nitrogen was contained in the base as opposed to being poured over top of the sample, providing a more consistent sample preparation and maintaining a more constant temperature. Stainless steel also is much easier to clean when the concentration of potassium ions present in the test equipment is an issue.

\section{CONCLUSION}

The primary goal of this research project was to define a method for the chemical extraction and analysis of the potassium content in muscle tissue. Initial methods were developed for spectrometric analysis through the testing of liquids, followed by a digestion of a banana. For the meat testing, the first method of digestion consisted of soaking the meat in acid and produced lower levels for potassium concentration. A better extraction method was developed by freeze fracturing the meat tissue, total digestion, and liquid extraction of potassium from the meat. This second method proved to be more effective at potassium extraction as an average increase of $1.54 \mathrm{~g} \mathrm{~K}^{+} / \mathrm{kg}$ was obtained from each meat sample tested.

\section{ACKNOWLEDGEMENTS}

- Pittsburgh Conference Memorial Undergraduate Instrumentation Grant for the Atomic Absorption Spectrometer

- Saint Francis University Chemistry Department

\section{REFERENCES}

1. Ehrlich, S.D. (2009, May 6). Potassium. Accessed 3 May 2011, Retrieved from http://www.umm.edu/altmed/articles/pot assium-000320.htm

2. Ellis, Kenneth J. Human Body Composition, $2^{\text {nd }}$ edition Heymsfield SB, Lohman TG, Wang ZM and Going SB, Eds. 2005 Human Kinetics.

3. S.J. Ridout, S.M. LoRusso, P.I. Fitzgerald, J.A. Pelberg, and D.N. Proctor, International Journal of Body Composition Research, Estimation of active cell mass in the human lower leg: feasibility of a regional ${ }^{40} \mathrm{~K}$ system, 2007, Vol. 5, Pgs. 131-136

4. Decuypere, J.D. Dr. Decuypere's nutrient charts: fruit charts, Accessed 4 May 2011, Retrieved from http://www.healthalternatives2000.com/f ruit-nutrition-chart.html.

5. Mayo Clinic, (2010, November 1). Potassium supplement oral route, parenternal route. Accessed 4 May 2011, Retrieved from: http://www.mayoclinic.com/health/druginformation/DR602373

6. "E326: Potassium Lactate" Food-Info. 9 Jun 2008, Accessed 3 May 2011, http://www.food-info.net/uk/e/e326.htm.

7. http://www.epa.gov/region1/info/testmet hods/pdfs/testmeth.pdf Accessed 11 September 2011 


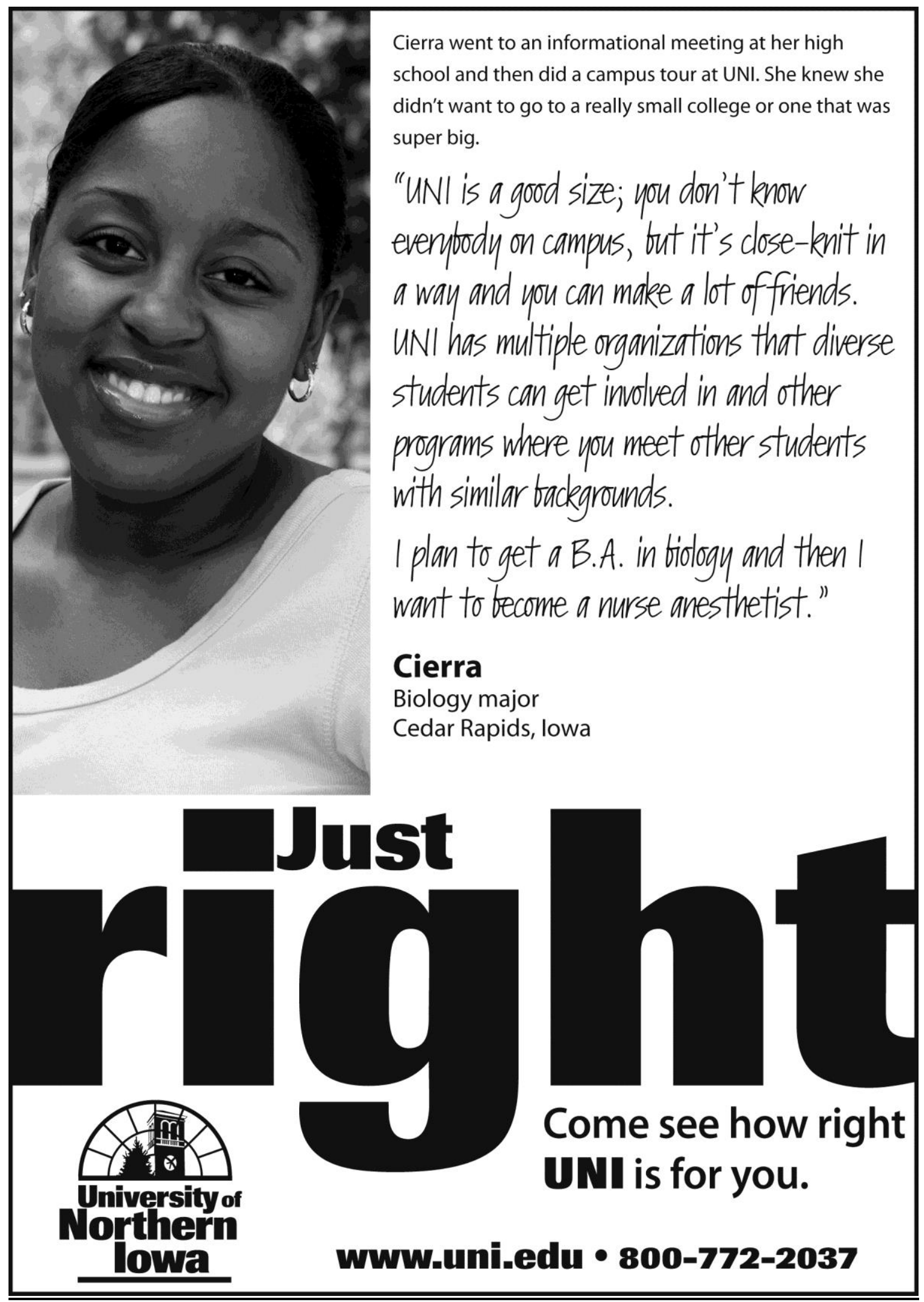

